\title{
Effect of topical ketanserin administration on intraocular pressure
}

\author{
C Costagliola, G Iuliano, M Rinaldi, V Russo, G Scibelli, L Mastropasqua
}

\begin{abstract}
The effect of topical ketanserin on intraocular pressure (IOP) in normotensive and hypertensive eyes was evaluated. The study was performed on 10 healthy volunteers and 10 glaucomatous patients. Systolic arterial blood pressure (SBP), diastolic arterial blood pressure (DBP), heart rate (HR), IOP, tonographic outflow facility, pupil diameter, corneal thickness, and tear secretion were recorded at baseline and at 1 hour intervals for 12 hours after topical administration of $0.5 \%$ ketanserin or placebo, given in a randomised, double masked, crossover fashion. The alternative treatment was given 1 week later. In all subjects ketanserin significantly lowered IOP, while no variations in SBP, DBP, HR, pupil diameter, corneal thickness, and tear secretion were found. When subjects received placebo no significant variations of IOP occurred. Total outflow facility, measured by conventional tonography, increased significantly after drug administration in all subjects. Ketanserin is effective up to 6 hours in control subjects and 9 hours in glaucomatous patients. The placebo did not induce any change in this component of the aqueous humour dynamic in normal or in glaucomatous eyes. The findings indicate that topical ketanserin might be added to the list of antiglaucomatous agents.

(Brf Ophthalmol 1993; 77: 344-348)
\end{abstract}

Ketanserin is an antihypertensive agent with predominantly serotonergic blocking properties and additional mild postsympatholytic action. ${ }^{12}$ Comparative trials have indicated that ketanserin is as effective as $\beta$ blockers or diuretics in reducing blood pressure in patients suffering from arterial hypertension. ${ }^{34}$

Recently, we reported that orally administered ketanserin also significantly reduced intraocular pressure (IOP) both in healthy volunteers ${ }^{56}$ and in glaucomatous patients ${ }^{7}$ by increasing the total outflow facility, measured by conventional tonography, and thus by reducing the outflow resistance. When topically applied, ketanserin lowers IOP in rabbits, cats, and monkeys. ${ }^{8-10}$ To date, no studies on the effect of topical ketanserin in humans have been reported.

The aim of this clinical trial was to verify whether ketanserin administered topically was able to reduce IOP in normal and glaucomatous eyes. Preliminary results have been reported elsewhere."

Patients and methods

This study included 10 glaucomatous patients (five men and five women, age range $40-50$ years) with IOP values greater than or equal to $22 \mathrm{~mm}$ $\mathrm{Hg}$ in each eye. All patients had visual field glaucomatous defects (nasal step, paracentral defects, temporal wedge, arcuate defect, and generalised depression of light sensitivity $)^{12}$ and were being treated with $\beta$ blocking agents alone or in combination with pilocarpine. Ten healthy age and sex-matched normotensive volunteers were used as controls.

All subjects received a detailed physical and ophthalmic examination. Subjects with systemic diseases, those with aphakia or visual acuity less than 20/200 in either eye, those wearing contact lenses and women of childbearing potential were excluded from the study. Informed consent to participate in this study was obtained from all subjects after they had been given a detailed description of the procedures to be used and of the aims of the study.

All other therapies were stopped before the start of the trial as well as caffeine containing beverages. After a washout period (21 days for $\beta$ blocking drugs or 4 days for pilocarpine) subjects received a drop $(50 \mu \mathrm{l})$ of $0.5 \%$ ketanserin (Sufrexal, Janssen, Belgium) or placebo in a randomised crossover double masked fashion. The drug formula was as follows: compound (ketanserin tartrate 6.898 mg, equivalent to $5 \mathrm{mg}$ ketanserin) was suspended together with $51 \cdot 80$ mg propylene glycol, $50 \mathrm{mg}$ anhydrous dextrose, $1.10 \mathrm{mg}$ tartaric acid, in about $912 \mathrm{mg}$ of injection water; placebo was constituted similarly but without the active compound.

At baseline heart rate (HR), systolic and diastolic blood pressure (SBP and DBP, respectively), pupil diameter, corneal thickness, IOP, tonographic outflow facility, tear secretion (Schirmer tests and breakup time test) were recorded. Following baseline measurements, patients received the treatment (ketanserin or placebo) and measurements were performed at hourly intervals for 12 hours, and repeated after 12 hours (the next morning). The alternative treatment was administered a week later, a time considered sufficient for a single dose ketanserin washout, ${ }^{13}$ using the same protocol.

Intraocular pressure was determined with a Goldmann tonometer mounted on a Haag-Streit slit-lamp. Two rapid readings were taken on one eye chosen at random and measurements averaged. Only one eye was analysed in this study. Arterial blood pressure was measured twice with the patient in a supine position and 120 seconds later with the patient standing, using a Riva-Rocci sphygmomanometer. Pupil diameter was measured in $0.5 \mathrm{~mm}$ increments using a pupil gauge kept close to the cornea and under constant illumination while subjects fixed on an object about 10 feet away with the other eye. ${ }^{14}$ Conventional tonography was performed 
Figure 1 Systolic and diastolic arterial blood pressure variations after topical administration of ketanserin and/or placebo. (A) Control subjects and $(B)$ glaucomatous patients after placebo. (C) Control subjects and $(D)$ glaucomatous patients after ketanserin. Bars indicate $S D$.
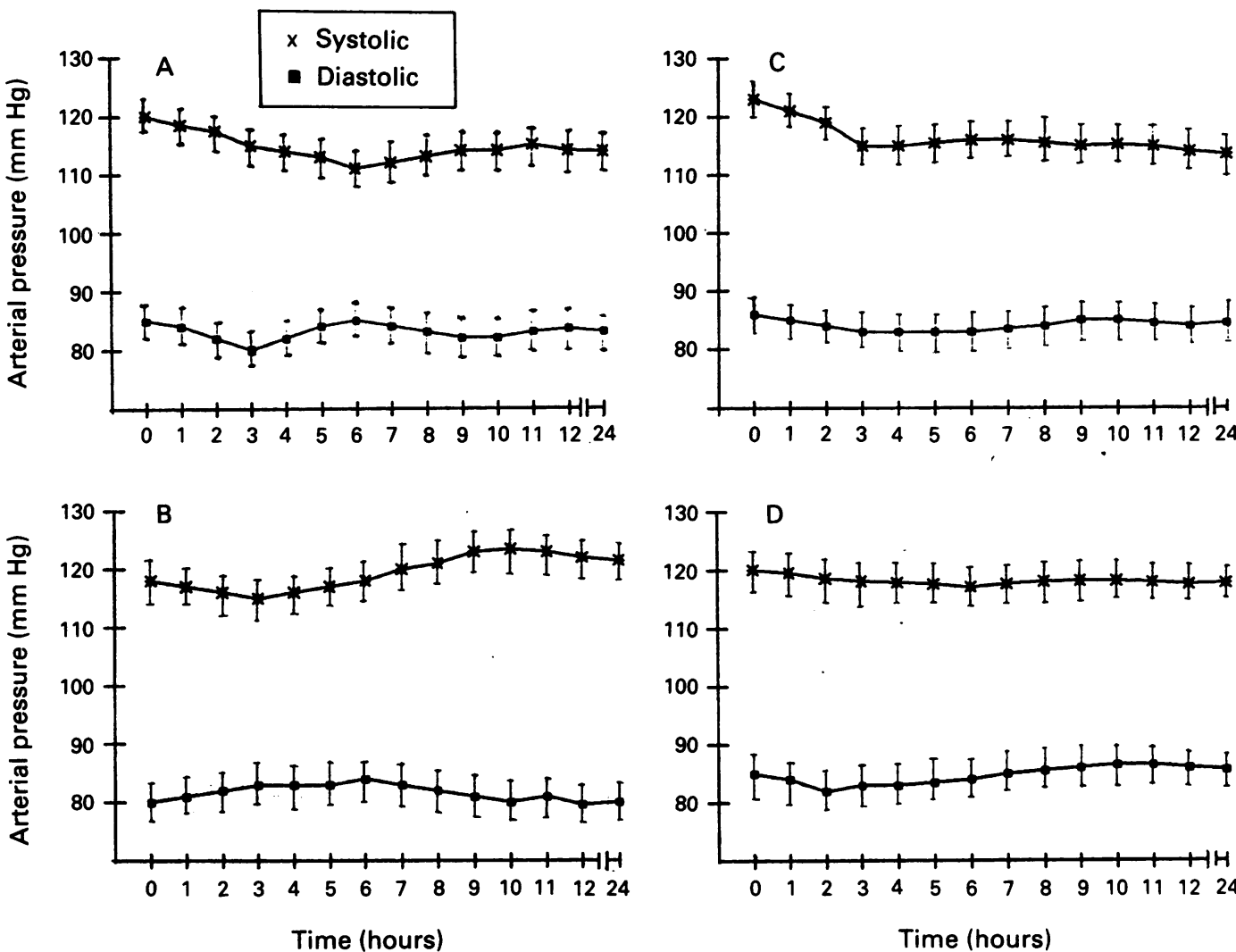

using a Glaukon (Optikon, Rome, Italy) computerised tonographic unit. Corneal thickness was determined ultrasonically using an Echo-Oculometer 300 (Radionics Medical Division, Sydney, Australia). Tear secretion was measured with the 5 minute filter paper method before and after corneal anaesthesia (Schirmer I and II tests). The tests were performed with standardised filter paper (Cooper Vision Ltd, Southampton) which was placed behind the third temporal of the lower lid, $5 \mathrm{~mm}$ in contact with the conjunctiva, the other $35 \mathrm{~mm}$ overhanging the lid margin. ${ }^{15} 16$ The stability of the precorneal tear film was assessed through the breakup time test (BUT). ${ }^{17}$ Applying 1\% fluorescein to the temporal conjunctiva the tear film became green; the interval, in seconds, between the last blink and the development of the first randomly distributed dry drops was defined as the BUT. ${ }^{19}$

Statistical analysis (Student's $t$ test) of the results was performed with an M24 Olivetti (Ivrea, Italy) personal computer.

\section{Results}

Figure 1 shows the SBP and DBP changes after a single topical administration of ketanserin and/ or placebo. Neither ketanserin nor placebo induced significant variations of arterial pressure in control subjects or in glaucomatous patients. Moreover, no significant variations of $H R$ were appreciated in both groups secondary to the placebo and/or ketanserin application (Table 1).

Figure 2 shows the changes in IOP after ketanserin and/or placebo administration in normal and glaucomatous eyes. In both groups ketanserin was able to reduce IOP significantly after 1 hour. At the subsequent measure-

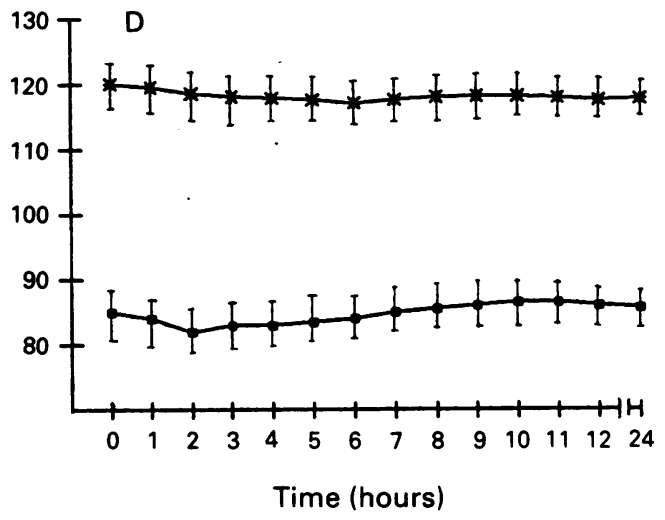

ments the degree of reduction was even more evident (normotensive eyes, from baseline: after 1 hour $-12 \cdot 5 \%$, after 2 hours $-13 \cdot 1 \%$, after 3 hours $-13 \cdot 5 \%$, after 4 hours $-13 \cdot 7 \%$, after 5 hours $-14 \cdot 1 \%$; hypertensive eyes from baseline: after 1 hour $-16 \%$, after 2 hours $-20 \%$, after 3 hours $-25 \%$, after 4 hours $-25 \cdot 1 \%$, and remained statistically different for up to 5 hours in control subjects and 9 hours in glaucomatous patients. In both groups the peaks were reached

Table 1 Heart rate variations after ketanserin and/or placebo administration in 10 glaucomatous patients and in 10 control subjects

\begin{tabular}{cll}
\hline $\begin{array}{l}\text { Time } \\
\text { (hours) }\end{array}$ & $\begin{array}{l}\text { Control } \\
\text { subjects }\end{array}$ & $\begin{array}{l}\text { Glaucomatous } \\
\text { patients }\end{array}$ \\
\hline $\begin{array}{ll}\text { After placebo } \\
\text { Baseline }\end{array}$ & & \\
1 & $82(5)$ & $79(3)$ \\
2 & $81(4)$ & $78(5)$ \\
3 & $80(3)$ & $81(4)$ \\
4 & $83(8)$ & $82(5)$ \\
5 & $82(5)$ & $83(6)$ \\
6 & $80(3)$ & $82(2)$ \\
7 & $79(7)$ & $81(4)$ \\
8 & $81(5)$ & $79(3)$ \\
9 & $82(4)$ & $80(5)$ \\
10 & $78(3)$ & $81(2)$ \\
11 & $80(2)$ & $82(3)$ \\
12 & $83(2)$ & $79(2)$ \\
24 & $82(5)$ & $81(5)$ \\
After ketanserin & $80(4)$ & $82(4)$ \\
Baseline & & \\
1 & $83(6)$ & $82(5)$ \\
2 & $82(5)$ & $79(3)$ \\
3 & $80(4)$ & $81(4)$ \\
4 & $81(3)$ & $80(4)$ \\
5 & $82(3)$ & $81(3)$ \\
6 & $79(4)$ & $82(2)$ \\
7 & $81(5)$ & $79(4)$ \\
8 & $80(4)$ & $80(3)$ \\
9 & $79(3)$ & $81(2)$ \\
10 & $81(5)$ & $79(4)$ \\
11 & $82(2)$ & $82(3)$ \\
12 & $81(4)$ & $83(2)$ \\
24 & $82(2)$ & $81(5)$ \\
& $80(3)$ & $79(2)$ \\
\hline
\end{tabular}

All values (beats/min) are mean (SD). p Not significant (Student's $t$ test). 


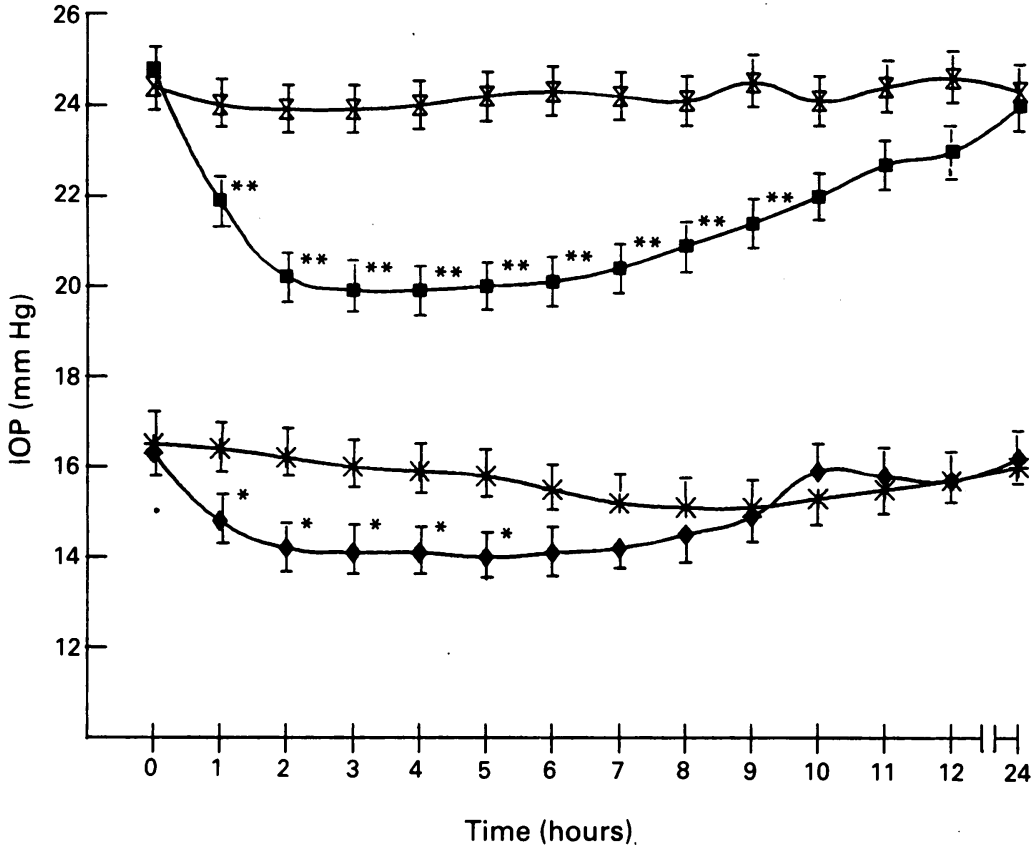

Figure 2 Intraocular pressure variations in controls after ketanserin ( ), controls after placebo (X), glaucomatous patients after ketanserin ( $\mathbf{\square}$, glaucomatous patients after placebo ( $\mathrm{X}){ }^{\star}{ }^{\star} p<0.05$ $\star \star p<0.01$ (Student's t test). Bars indicate $S D$. after 3 to 4 hours. Placebo did not induce any significant variation of IOP in either groups.

Changes in aqueous humour outflow facility, measured by conventional tonography, are reported in Table 2 . While placebo did not affect this parameter, 1 hour after ketanserin administration there was a significant increase of the tonographic outflow facility value in glaucomatous patients $(+24.8 \%, \mathrm{p}<0.05)$. At the subsequent measurements the increase in total outflow facility was even greater $(+40 \%$ after 2 hours, $\mathrm{p}<0.01$; $+43 \%$ after 3 hours, $\mathrm{p}<0.01$ ); normotensive eyes also showed a significant increase in total outflow facility. The levels obtained slowly decreased to insignificant values

Table 2 Tonographic outflow variations facility after ketanserin and/or placebo administration in 10 control subjects and in 10 glaucomatous patients

\begin{tabular}{|c|c|c|}
\hline $\begin{array}{l}\text { Time } \\
\text { (hours) }\end{array}$ & $\begin{array}{l}\text { Control } \\
\text { subjects }\end{array}$ & $\begin{array}{l}\text { Glaucomatous } \\
\text { patients }\end{array}$ \\
\hline \multicolumn{3}{|c|}{ After placebo } \\
\hline Baseline & $0.21(0.01)$ & $0 \cdot 18(0.02)$ \\
\hline 1 & $0.22(0.02)$ & $0.17(0.01)$ \\
\hline 2 & $0.23(0.02)$ & $0.18(0.02)$ \\
\hline 3 & $0.24(0.02)$ & $0.19(0.01)$ \\
\hline 4 & $0.23(0.03)$ & $0.18(0.02)$ \\
\hline 5 & $0.23(0.02)$ & $0.20(0.03)$ \\
\hline 6 & $0.22(0.01)$ & $0.19(0.02)$ \\
\hline 7 & $0.24(0.03)$ & $0.18(0.01)$ \\
\hline 8 & $0.23(0.02)$ & $0.19(0.01)$ \\
\hline 9 & $0.22(0.02)$ & $0.17(0.02)$ \\
\hline 10 & $0.21(0.01)$ & $0.18(0.02)$ \\
\hline 11 & $0.22(0.02)$ & $0.20(0.03)$ \\
\hline 12 & $0.20(0.02)$ & $0.17(0.01)$ \\
\hline 24 & $0.22(0.01)$ & $0.19(0.02)$ \\
\hline \multicolumn{3}{|c|}{ After ketanserin } \\
\hline Baseline & $0.20(0.01)$ & $0 \cdot 15(0 \cdot 02)$ \\
\hline 1 & $0.25(0.02)^{\star}$ & $0.23(0.01)^{\star}$ \\
\hline 2 & $0.26(0.01)^{\star}$ & $0.25(0.02) \dagger$ \\
\hline 3 & $0.27(0.02)^{\star}$ & $0.26(0.02) \dagger$ \\
\hline 4 & $0.27(0.02)^{\star}$ & $0.26(0.01) \dagger$ \\
\hline 5 & $0.26(0.01)^{\star}$ & $0.25(0.02) \dagger$ \\
\hline 6 & $0.25(0.01)^{\star}$ & $0.24(0.03) \dagger$ \\
\hline 7 & $0.24(0.02)$ & $0.23(0.02)^{\star}$ \\
\hline 8 & $0.23(0.01)$ & $0.23(0.01)^{\star}$ \\
\hline 9 & $0.23(0.02)$ & $0.23(0.02)^{\star}$ \\
\hline 10 & $0.22(0.01)$ & $0 \cdot 19(0.03)$ \\
\hline 11 & $0.22(0.02)$ & $0.17(0.03)$ \\
\hline 12 & $0.21(0.02)$ & $0.16(0.02)$ \\
\hline 24 & $0.22(0.01)$ & $0.15(0.01)$ \\
\hline
\end{tabular}

All values $\left(\mu \mathrm{l} \mathrm{min}{ }^{-1} \mathrm{~mm} \mathrm{Hg}^{-1}\right)$ are mean $(\mathrm{SD})$

Student's $t$ test was used for statistical analysis $\left.{ }^{\star}\right) \mathrm{p}<0.05$; $(t) p<0 \cdot 01$.
Table 3 Pupil diameter variations after ketanserin and/or placebo administration in 10 glaucomatous patients and in 10 control subjects

\begin{tabular}{lll}
\hline $\begin{array}{l}\text { Time } \\
\text { (hours) }\end{array}$ & $\begin{array}{l}\text { Control } \\
\text { subjects }\end{array}$ & $\begin{array}{l}\text { Glaucomatous } \\
\text { patients }\end{array}$ \\
\hline After placebo & & \\
Baseline & $4 \cdot 5(0 \cdot 7)$ & $4 \cdot 3(0 \cdot 5)$ \\
1 & $4 \cdot 2(0 \cdot 5)$ & $4 \cdot 1(0 \cdot 8)$ \\
2 & $3 \cdot 9(0 \cdot 4)$ & $4 \cdot 2(0 \cdot 7)$ \\
3 & $4 \cdot 2(0 \cdot 8)$ & $3 \cdot 9(0 \cdot 3)$ \\
4 & $4 \cdot 4(0 \cdot 6)$ & $4 \cdot 2(0 \cdot 4)$ \\
5 & $4 \cdot 2(0 \cdot 7)$ & $4 \cdot 5(0 \cdot 6)$ \\
6 & $3 \cdot 9(0 \cdot 4)$ & $4 \cdot 4(0 \cdot 5)$ \\
7 & $4 \cdot 1(0 \cdot 5)$ & $4 \cdot 2(0 \cdot 7)$ \\
8 & $4 \cdot 3(0 \cdot 8)$ & $4 \cdot 6(0 \cdot 4)$ \\
9 & $4 \cdot 5(0 \cdot 3)$ & $4 \cdot 3(0 \cdot 6)$ \\
10 & $4 \cdot 1(0 \cdot 5)$ & $4 \cdot 5(0 \cdot 5)$ \\
11 & $4 \cdot 3(0 \cdot 1)$ & $4 \cdot 4(0 \cdot 3)$ \\
12 & $3 \cdot 9(0 \cdot 7)$ & $4 \cdot 6(0 \cdot 2)$ \\
24 & $4 \cdot 4(0 \cdot 4)$ & $3 \cdot 9(0 \cdot 6)$ \\
After ketanserin & & \\
Baseline & $4 \cdot 4(0 \cdot 5)$ & $4 \cdot 1(0 \cdot 6)$ \\
1 & $4 \cdot 6(0 \cdot 6)$ & $3 \cdot 9(0 \cdot 7)$ \\
2 & $4 \cdot 2(0 \cdot 8)$ & $4 \cdot 5(0 \cdot 5)$ \\
3 & $3 \cdot 9(0 \cdot 4)$ & $4 \cdot 3(0 \cdot 2)$ \\
4 & $4 \cdot 3(0 \cdot 5)$ & $4 \cdot 1(0 \cdot 3)$ \\
5 & $3 \cdot 9(0 \cdot 7)$ & $4 \cdot 2(0 \cdot 2)$ \\
6 & $4 \cdot 5(0 \cdot 3)$ & $3 \cdot 9(0 \cdot 4)$ \\
7 & $4 \cdot 4(0 \cdot 1)$ & $4 \cdot 5(0 \cdot 3)$ \\
8 & $4 \cdot 2(0 \cdot 4)$ & $4 \cdot 3(0 \cdot 2)$ \\
9 & $4 \cdot 4(0 \cdot 5)$ & $4 \cdot 5(0 \cdot 4)$ \\
10 & $4 \cdot 1(0 \cdot 3)$ & $3 \cdot 8(0 \cdot 3)$ \\
11 & $3 \cdot 9(0 \cdot 6)$ & $4 \cdot 3(0 \cdot 2)$ \\
12 & $4 \cdot 4(0 \cdot 5)$ & $4 \cdot 5(0 \cdot 5)$ \\
24 & $4 \cdot 6(0 \cdot 4)$ & $4 \cdot 4(0 \cdot 2)$ \\
\hline & & \\
\hline & &
\end{tabular}

All values (mm) are mean (SEM)

p Not significant (Student's $t$ test)

after 6 hours in control subjects and 9 hours in glaucomatous patients. In both groups the peaks were reached after 3-4 hours.

As can be seen from Table 3 there were no significant variations in pupil diameter after administration of either ketanserin or placebo to both groups.

The Schirmer and break up time tests did not show any significant difference in either group when patients were receiving the drug or when placebo was administered. No significant variations of the corneal thickness were noted. Finally, there were no adverse effects after the application of either ketanserin or placebo (that is, conjunctival hyperaemia, aqueous humour flare, anterior chamber cellular response, etc).

\section{Discussion}

Our results show that topical administration of ketanserin significantly reduces IOP in normotensive and hypertensive human eyes. Moreover, the magnitude of IOP reduction was greater than that observed using the oral route ${ }^{5-7}$ and was consistent with previous experimental studies in animals ${ }^{8-10}$ and with our preliminary findings in humans. ${ }^{11}$

The mechanism by which ketanserin decreases IOP in humans could be explained on the basis of the increase in total outflow facility, as demonstrated by the conventional tonography. Previously, both Chang and coworkers ${ }^{8}$ and Conway and Lewis ${ }^{10}$ suggested that ketanserin exerted its effects on IOP by suppressing aqueous humour formation via antagonism of $\alpha$ adrenoreceptors. But the absence of variations in pupil diameter, together with the tonographic results are more consistent with an S2-serotonergic blockade than with $\alpha_{1}$ antagonism, although our data are not able to exclude completely a dual action mech- 
anism. Serotonin is present in mammalian iris ciliary bodies and corneas at higher concentrations than in non-mammalian species. ${ }^{20} \mathrm{~A}$ transmitter role for serotonin in the retina has been well established. ${ }^{21}$ In contrast, a role for serotonin in the iris ciliary body has not yet been found. When injected into the anterior chamber, serotonin produces an increase both in $\mathrm{IOP}^{22}$ and in the protein concentration. ${ }^{23}$ Ketanserin has an inhibitory effect on the serotonin stimulated accumulation of inositol phosphates in the iris ciliary body ${ }^{24}$; on the contrary, the serotonin response is insensitive to atropine and prazosin, indicating that the serotonin effect is mediated by receptors that are distinct from $\alpha_{1}$ adrenergic and muscarinic cholinergic receptors. Thus, both experimental and clinical evidence confirms that the inhibitory action of ketanserin is not mediated by an antagonism of $\alpha$ adrenoreceptors, rather it is due to a specific blocking effect on the serotonin-2 receptor subtype.

The increase in tonographic outflow facility induced by ketanserin is as effective as pilocarpine, ${ }^{25}$ without its side effects (myosis, iris congestion, etc).$^{26}$ Thus, ketanserin seems to act where $\beta$ adrenoreceptor blocking agents are known to have little or no effect. ${ }^{27} 28$

Ketanserin administration does not induce significant variations of tear secretion and does not alter the stability of the lacrimal film. Rather, it is not unrealistic to hypothesise that ketanserin is able to improve tear secretion and to preserve the stability of the lacrimal film directly, because of the lack of effects on $\beta$ agonist receptors ${ }^{29}$ and indirectly, by improving the blood flow to the lacrimal gland..$^{30}$ In this sense, the compound does not exhibit the well known ocular side effects induced by $\beta$ blockers ${ }^{31}-$ that is, dry eye and superficial keratitis, which frequently occur in patients undergoing treatment.

Topical administration of ketanserin did not result in significant variations of SBP, DBP, and HR. $\beta$ Blockers, the most effective drugs at present in the treatment and management of glaucoma, are reported to have systemic cardiovascular and pulmonary side effects - that is, decreased cardiac rate and myocardial contractility, prolongation of atrioventricular conduction, reduction of blood pressure, ${ }^{32-35}$ and bronchoconstriction. ${ }^{36}{ }^{37}$ On the contrary, ketanserin seems to be particularly suited for the treatment of patients with congestive heart failure and other low output shock conditions; it restores depressed cardiac function and reduces cardiac oxygen consumption, ${ }^{29} 38$ without effects on atrioventricular conduction. Moreover, it does not influence symptoms and indices of airway resistance in patients with asthma because it has no detrimental effects on the bronchial tree. ${ }^{39}$

The lack of all these side effects together with its efficacy in lowering IOP puts ketanserin in a more favourable position when compared with $\beta$ blocking agents in the treatment of glaucoma. Moreover, the analysis of the response curves suggests that two or three daily applications will manage IOP in glaucomatous patients. Further studies based on long term follow up are needed to verify the real effectiveness of this novel antiglaucomatous drug.
Thanks are due to Mr A Giacoia and Mr S Rosolia for their skilful technical assistance.

1 Kalkman HO, Timmermans PB, van Zwieten PA. Characterization of the antihypertensive properties of ketanserin ization of the antihypertensive properties of ketanserin 2 Marwood JF, Stokes GS. Serotonin (5-HT) and its antagonists: involvement in the cardiovascular system. Clin Exp Pharmacol Physiol 1984; 11: 439-56.

3 Hedner T, Persson B, Berglund G. Ketanserin a novel 5-hydroxytryptamine antagonist: monotherapy in essential hypertension. Brf Clin Pharmacol 1983; 16: 121-5.

4 Ferrara LA, Fasano ML, Soro S, Pasanisi F, Mancini M. Antihypertensive efficacy of a combination of ketanserin and thiazide in hypertensives older than 50 years. 7 Cardiovasc Pharmacol 1987; 47: 689-98.

5 Costagliola C, Fasano ML, Ferrara LA, Iuliano G. Effects of ketanserin on intraocular pressure. Proc Fourth Eur Meeting on Hypertension, Milan, Italy, 1989: 42.

6 Costagliola C, Fasano ML, Iuliano G, Ferrara LA. Effect of ketanserin on intraocular pressure. Cardiovasc Drug Ther 1990; 4: 95-7

7 Costagliola C, Scibelli G, Fasano ML, Ferrara LA, Mastropasqua $L$. Effect of oral ketanserin administration on intraocular pressure in glaucomatous patients. Exp Eye Res 1991; 52: 507-10.

8 Chang FW, Burke JA, Potter DE. Mechanism of the ocular hypotensive action of ketanserin. $\mathcal{F}$ Ocular Pharmacol 1985 ; 1: $137-47$.

9 Krootila K, Palkama A, Uusitalo H. Effect of serotonin and its antagonist (Ketanserin) on intraocular pressure in the rabbit. F Ocular Pharmacol 1987; 3: 279-90.

10 Conway JL, Lewis FA. Ocular hypotensive action of ketanserin. Invest Ophthalmol Vis Sci 1989; 30 (suppl): 24

11 Costagliola C, Iuliano G, Mastropasqua L. Topical ketanserin administration and intraocular pressure in man. Proc 9th Intern Congr Eye Res (ICER), Helsinki, Finland, 1990: 107.

12 Hodapp E. Computerized perimetry in glaucoma. In: Whalen WR, Spaeth GL, eds. Computerized visual fields. Thorofare, NJ, USA: Slack Incorporated Ltd, 1985: 197-238.

13 Kurowski $M$. Bioavailability and pharmacokinetics of ketanserin in elderly subjects. Eur f Clin Pharmacol 1985; 28 : 411-7.

14 Karnezis TA, Murphy MB, Weber RR, Nelson KS, Tripathi BJ, Tripathi RC. Effects of selective dopamine-1-receptor activation on intraocular pressure in man. Exp Eye Res 1988; 47: 689-98.

15 Schirmer O. Studien zur Physiologie und Pathologie der Tranenbsoderung und Tranenadfuhr. Graefes Arch Clin Exp Ophthalmol 1903; 56: 197-291.

16 vanSetten GB, Stephens R, Tervo T, Salonen EM, Tarkkanen A, Vaheri A. Effects of the Schirmer test on the fibrinolytic system in the tear fluid. Exp Eye Res 1990; 50: 135-41.

17 Norn MS. Dessication of the precorneal film. I Corneal wetting time. Acta Ophthalmol 1969; 47: 865-70.

8 Lemp MA, Hamill JR. Factors affecting the tear film break-up time in normal eyes. Arch Ophthalmol 1973; 89: 103-12.

19 Rolando M. Semeiotica della patologia del film lacrimale. In Calabria G, Rolando M, eds. Fisiopatologia del film lacrimale. Rome, Italy: Soc Ophthalmol Ital, 1984: 97-132.

20 Osborne NN. The occurrence of serotonergic nerves in bovine cornea. Neurosci Lett 1983; 35: 15-8.

21 Osborne NN. Indoleamine in the eye with special reference to the serotonergic neurones of the retina. In: Osborne NN, the serotonergic neurones of the retina. In: Osborne NN, Chadar GJ, eds. Progress

22 Osborne NN, Tobin AB. Serotonin accumulating cells in the iris-ciliary body and cornea of various species. Exp Eye Res 1987; 44: 731-46.

23 Palkama A, Lehtosalo J, Uusitalo H. 5-Hydroxytryptamine receptors in the cornea and ciliary processes of the rabbit and human eyes. Ophthalmic Res 1984; 16: 207-8.

24 Tobin AB, Unger W, Osborne NN. Evidence for the presence of serotonergic nerves and receptors in the iris-ciliary body

25 Bill A, Walinder PE. The effects of pilocarpine on the dynamics of aqueous humor in a primate (Macaca irus) Invest Ophthalmol Vis Sci 1966; 5: 170-5.

26 Duke-Elder S. System of ophthalmology. Vol XI (VIII). St Louis: Mosby, 1966: 510.

27 Yablonski ME, Zimmerman T, Walman S, Becker B. A fluorophotometric study of the effect of topical timolol on aqueous humor dynamics. Exp Eye Res 1978; 27: 135-42.

28 Yablonski ME, Novack GD, Burke PJ, Cook DJ, Harmon G The effect of levobunolol on aqueous humor dynamics. Exp Eye Res 1987; 44: 49-54.

29 Symoens J, Janssens M. Ketanserin: a novel cardiovascular drug. Drug Devel Res 1986; 8: 159-72.

30 Coffman JD. Raynaud's disease: pathogenesis and treatment. Proc Fourth Eur Meeting on Hypertension, Milan, Italy, 1989: 14.

31 Aberg G, Adler G, Wikberg J. Inhibition and facilitation of lacrimal flow by beta-adrenergic drugs. Acta Ophthalmol 1979; 57: 225-31.

32 Dermailly $P$, Lehner $M$, Etienne $R$, Trepsat $C$, Hout $J$ Raynaud G, et al. Rèsultat d'une ètude á móyen terme en double avengle comparant le malèate de timolol l'èphinèphrine sur 120 patients parteur d'un glaucome l'èphinèphrine sur 120 patients parteur d'un glaucome

33 McMahon CD, Shaffer RM, Hoskins HD, Hetherington Jr J. Adverse effects experienced by patients taking timolol. $A m \tilde{J}$ Ophthalmol 1979; 88: 736-41.

34 Leier CV, Baker ND, Weber PA. Cardiovascular effects of ophthalmic timolol. Ann Intern Med 1986; 104: 197-9. 
35 Collingnon P. Cardiovascular and pulmonary effects of betablocking agents: implications for their use in ophthal mology. Surv Ophthalmol 1989; 33 (suppl): 455-6.

36 Schoene RB, Abuan T, Ward RL, Beasley CH. Effects of topical betazolol, timolol and placebo on pulmonary function in asthmatic bronchitis. Am $\mathcal{F}$ Ophthalmol 1984; 97: 86-92. 37 Weinreb RN, vanBuskirk EM, Cherniack R, Drake MM.
Long-term betaxolol therapy in glaucoma patients with pulmonary disease. Am $f$ Ophthalmol 1988; 106: 162-7.

38 Dermoulin JC, Bertholet M, Soumagne D, David JL, Kulbertous HE. 5-HT2-receptor blockade in the treatmen of heart failure. A preliminary study. Lancet 1981; i 1186-8.

39 Cazzola M, D'Amato G, Lobefalo G, Guillaro B, Sepe S Assogna $G$, et al. Ketanserin a new blocking agent of serotonin S2 receptors: respiratory functional effects in chronic obstruction of the airways. Chest 1987; 92: 863-7. 